\title{
Erratum to: Cooperative Communication Protocols in Wireless Networks: Performance Analysis and Optimum Power Allocation
}

\author{
Weifeng Su • Ahmed K. Sadek • K. J. Ray Liu
}

Published online: 2 April 2011

(C) Springer Science+Business Media, LLC. 2011

\section{Erratum to: Wireless Pers Commun (2008) 44:181-217 DOI 10.1007/s11277-007-9359-z}

The third author's name was incorrectly captured in the original publication. It is correct in this erratum.

The online version of the original article can be found under doi:10.1007/s11277-007-9359-z.

W. Su $(\bowtie)$

Department of Electrical Engineering, State University of New York (SUNY) at Buffalo, Buffalo, NY 14260, USA

e-mail: weifeng@eng.buffalo.edu

A. K. Sadek · K. J. R. Liu

Department of Electrical and Computer Engineering, University of Maryland,

College Park, MD 20742, USA

e-mail: aksadek@eng.umd.edu

K. J. R. Liu

e-mail: kjrliu@eng.umd.edu 